\title{
Psychosocial Predictors of Compliance with Speed Limits and Alcohol Limits by Spanish Drivers: Modeling Compliance of Traffic Rules
}

\section{Rebeca Bautista ${ }^{1,2, *}$, Esther Sitges ${ }^{1,2, \dagger}$ and Sonia Tirado ${ }^{2, \dagger}$}

1 CRÍMINA Center for the Study and Prevention of Delinquency, University Miguel Hernández de Elche, Avda. de la Universidad s/n, Elche 03202, Spain; E-Mail: esther.sitges@umh.es

2 Health Psychology Department, University Miguel Hernández de Elche, Avda. de la Universidad s/n, Elche 03202, Spain; E-Mail: sonia.tirado@umh.es

$\dagger$ These authors contributed equally to this work.

* Author to whom correspondence should be addressed; E-Mail: rbautista@umh.es; Tel.: +34-966-658-383 (ext. 8383); Fax: +34-966-658-904.

Academic Editor: Frank Pasquale

Received: 2 July 2015 / Accepted: 1 September 2015 / Published: 9 September 2015

\begin{abstract}
To prevent dangerous driving behaviors, the Spanish government has implemented public policies focused primarily on increasing the harshness of sanctions for violations of traffic laws. However, empirical evidence has demonstrated that other factors, such as social norms and one's own value system, have an impact on people's motivation to obey the law. A telephone survey was administered to a random sample of 570 Spanish drivers in order to determine the role played by each of these factors in compliance with two of the most flouted traffic rules. Logistic regression of the data allowed for the construction of models and arrive at the following conclusions: (1) social influence exerted by the reference group is a determining factor in compliance with both traffic laws; (2) legitimacy factors play an important role in complying with alcohol limits; and (3) variables from the deterrence approach only influenced compliance with speed limits, and then only moderately. The results of the present study suggest a need for a review of current public policy approaches for the prevention of dangerous driving behaviors.
\end{abstract}

Keywords: compliance; deterrence; legitimacy; road safety; social influence 


\section{Introduction}

Scientific study of law-related human behavior has taken different approaches to the question of whether the decision to violate a norm or not is determined by the adverse consequences of a violation. For example, the Deterrence Model [1] emphasizes the importance of the features of formal punishment on decision-making and driver control. This model hypothesizes that the greater the perceived certainty, severity, and celerity of sanctions, the lower the likelihood that an individual will violate the law. With respect to perceived certainty, most studies support, albeit modestly, the existence of a relationship between perceived risk of punishment and informed noncompliance [2-5]. Regarding perceived severity, although some authors have found evidence to support an inverse relationship with legal violations [6], other researchers have found that its effects are inconsistent [5]. There appears to be greater agreement that the preventive impact is less than that of perceived certainty [6]. Finally, although classical theorists considered the basis of the association between deviant behavior and its consequences to be the temporal proximity of punishment [7], other studies have shown that, for some individuals, the cost of delayed punishment is greater than that of swift punishment [8]. Some researchers have even concluded that empirical evidence does not support the influence of this factor on deviant behavior [6]. It may be inferred from the meta-analysis of Pratt, Cullen, Blevins, Daigle, and Dansen [9], and in support of what has just been stated, that the preventive effects of the variables of the Dissuasion Model on deviance are modest. As suggested by Meier, Burkett, and Hickman [10], the costs of a transgression go beyond the mere cost of the formal sanctions applied by the legal system. Judging from emerging public policies, however, the legal system appears to assume that the key to preventing deviance is rooted in increasing formal punishments, leaving aside other elements that may be more efficient. Empirical evidence suggests that other factors such as, for example, informal social norms and sanctions, or an individual's own value system, may have significant preventive effects $[1,11,12]$.

With respect to the first of these factors, most of the research done in the area of social influence throughout the years shows that social scientists have great interest in laws and their influence on behavior. Specifically, according to the Focus Theory of Normative Conduct developed by Cialdini, Reno, and Kallgren [13] and by Cialdini, Kallgren, and Reno [14] there are two types of social norms that may influence individuals' behavior. On the one hand, the so-called descriptive norms derive from what other people do, and represent behavior considered typical or normal in a particular context. This type of influence is most likely to operate in situations that are new or ambiguous for an individual [15], especially when it comes from people who are similar to him/her [16]. On the other hand, injunctive norms are what most people approve or disapprove of - what should or should not be done-and they make up the moral rules of the group [17], behaviors imposed by others through informal sanctions, such as social disapproval.

Nevertheless, to say that people's actions are basically conditioned by the threat of external sanctions, whether formal or informal, is too simplistic to explain human behavior in any context. Today, social psychologist Tom R. Tyler's research provides a frame of reference for studying compliance with the law using the administration of formal or informal external punishments to motivate obedience and respect for laws and authorities. In his opinion, the outlay of resources necessary for the threat of punishment to be perceived as real and, thereby, serve as a deterrent to 
potential offenders is so great that-given that the literature does not show consistent preventive effects for formal punishment, and the effects it does find are small $[5,18,19]$ - these types of social control strategies relied upon by most countries to encourage compliance with the law turn out to be, at best, inefficient [20]. Beginning with the Self-Regulation Model [20], then, the influence of personal values on behavior is seen as greater than the influence of the perception of external costs and benefits expected from the behavior, and those values are seen to motivate voluntary compliance with laws, as well as cooperation with legal authorities. The central value in this model is legitimacy, defined as the quality possessed by an authority, a law or an institution that is operationalized as support shown for legal authorities. Some studies show that a person's value system is important for motivating compliance and also that its effect is greater than that of perceptions of the risk of formal punishment $[19,21]$. The literature provides evidence that the power of values' influence on behavior is so great that it is less likely that individuals will comply with laws that they consider immoral or contrary to their value system [19]; it is more likely that they will comply with laws that are consistent with their morals $[22,23]$. In the area of road safety, it has been found that the likelihood of exceeding alcohol limits is lower among those who think the law is legitimate than among those who think the opposite [24]. Therefore, in order to promote compliance using alternative models to the threat of formal sanctions it is important that laws, as well as legal authorities' behavior and decisions, reflect, to the greatest possible extent, the moral standards shared by the majority of individuals.

Given the difference in the models that explain compliance with speed and alcohol limit laws as codified in the Traffic and Road Security Law 25/2009 of Spain, the objective of this study is to build a model for analysis of the joint influence exerted by each factor derived from the different investigative traditions described above. The reason for focusing the research on these particular laws is that they are the two laws most violated by Spanish drivers; excess speed and alcohol consumption are two of the factors most associated with traffic accidents [25]. Both laws had been enforced only administratively before the reform of the Penal Code's traffic and road safety laws in 2007 and 2010 and their violation now constitute crimes that may be punished even with the deprivation of liberty.

\section{Methods}

\subsection{Participants}

The sample studied was made up of 570 participants selected at random from the universe of individuals residing in every autonomous community of Spain (Table 1). The participants met two criteria for inclusion: (1) having a driver's license for which the minimum age was at least 18; and (2) driving more than zero miles per week. Of the 570 participants, 304 are men $(53.3 \%)$ and 266 are women $(46.7 \%)$ between the ages of 18 and $75(\bar{X}=44.23$; $\mathrm{SD}=13.5)$.

Table 1. Geographic distribution of the sample.

\begin{tabular}{ccc}
\hline Autonomous Community & $\boldsymbol{f}$ & $\boldsymbol{\%}$ \\
\hline Andalucía & 123 & 21.6 \\
Aragón & 24 & 4.2 \\
Principado de Asturias & 20 & 3.5 \\
Islas Baleares & 11 & 1.9 \\
\hline
\end{tabular}


Table 1. Cont.

\begin{tabular}{ccc}
\hline Autonomous Community & $\boldsymbol{f}$ & $\boldsymbol{\%}$ \\
\hline Canarias & 13 & 2.3 \\
Cantabria & 6 & 1.1 \\
Castilla y León & 24 & 4.2 \\
Castilla-La Mancha & 35 & 6.1 \\
Cataluña & 83 & 14.6 \\
Comunidad Valenciana & 74 & 13 \\
Extremadura & 17 & 3 \\
Galicia & 31 & 5.4 \\
Comunidad de Madrid & 66 & 11.6 \\
Región de Murcia & 2 & 0.3 \\
Comunidad Foral de Navarra & 5 & 0.8 \\
País Vasco & 26 & 4.6 \\
La Rioja & 10 & 1.8 \\
N $=570$ & & \\
\hline
\end{tabular}

\subsection{Variables}

\subsubsection{Dependent Variable}

Informed compliance with laws: compliance with traffic laws was operatized as the frequency with which the person had driven "at a speed higher than established limits"/"having consumed a sufficient quantity of alcohol for punishment" in the past year. A response scale from $0=$ "Never" to $10=$ "Always" was used.

However, for the logistic regression analysis, both dependent variables were dichotomized, so that $0=$ "Has failed to comply with the law with any frequency in the past year" and 1 = "Has always complied with the law in the past year".

\subsubsection{Independent Variables}

The independent variables were grouped into (a) deterrence; (b) social influence; and (c) legitimacy of the law.

(a) Deterrence variables

\section{Severity}

Severity of punishment: An ordinal variable assessed for each of the laws on a scale from $0=$ "The sanctions applied in different situations of excess speed/alcohol consumption seem very light to me" to $10=$ "The sanctions applied in different situations of excess speed/alcohol consumption seem very harsh to me." 


\section{Certainty}

Perception of the risk of getting caught by: (a) police: an ordinal variable with a response scale from $0=$ "If I drove too fast or drove drunk it would be highly unlikely that the police would stop me" to $10=$ "If I drove too fast or drove drunk it is extremely likely that the police would stop me"; (b) radar: an ordinal variable assessed according to the speed limit laws on a scale from $0=$ "If I drove too fast it would be extremely unlikely that I would be detected by radar" to $10=$ "If I drove too fast it would be extremely likely that I would be detected by radar."

Perception of the risk of sanctions: an ordinal variable with a response scale from $0=$ "If the police stopped me or radar detected me driving too fast or drunk, I am sure I would not be punished" to $10=$ "If the police stopped me or radar detected me driving too fast or drunk, I am sure I would be punished."

Perception of the risk of having a traffic accident: an ordinal variable with a response scale from $0=$ "If I drove above the speed limit or drove drunk it is extremely unlikely that I would have a traffic accident" to $10=$ "If I drove above the speed limit or drove drunk it is extremely likely that I would have a traffic accident."

\section{Experience}

Experience with sanctions: a nominal dichotomous variable that assesses whether the subject has ever been sanctioned for exceeding speed limits or alcohol limits.

(b) Social Influence Variables

Prescriptive Norm

An ordinal variable that assesses the degree to which the person believes that the people most important to him/her would disapprove of the fact that he/she had failed to comply with each of the laws on a scale from $0=$ "They would not disapprove at all" to $10=$ "They would strongly disapprove".

\section{Descriptive Norm}

People: an ordinal variable that assesses the frequency of people who the person believes drive with excessive speed/alcohol on a scale from $0=$ "No one does it" to $10=$ "Everyone does it".

Group: An ordinal variable which assesses the frequency with which the participant believes the people closest to him/her drive with excessive speed/alcohol on a scale from $0=$ "None of them do it" to $10=$ "All of them do it."

(c) Legitimacy Variables

Legitimacy of the Law and authorities

Moral judgment of the law: an ordinal variable that assesses how bad the subject believes it is to drive too fast or drive drunk, on a scale of $0=$ "It is not bad at all" to $10=$ "It is entirely bad". 
Adequacy of the limits established by the law: an ordinal variable that assesses the perceived adequacy of the speed/alcohol limits on a scale of $0=$ "The limits are not at all adequate" to $10=$ "The limits are entirely adequate".

Valuation of the limits established by the law: An ordinal variable with the following three categories:

- Driving faster or with a higher level of alcohol should be permitted.

- Speed/alcohol limits should be stricter.

- Current speed/alcohol limits are appropriate.

Feeling of Obligation to Obey the Law: An ordinal variable, assessed with the scale utilized by Oceja, Fernández-Dols, González, Jiménez, and Berenguer [26] and by Tyler [19]. It is composed of six items related to the tendency toward obeying the law and authorities. The response scale for each item ranges from $0=$ "Disagree strongly" to $10=$ "Agree strongly". The total score of the variable is the sum of the scores for each of the items. High scores reflect a strong feeling of obligation to obey the law.The psychometric analyses performed indicate that the scale has an acceptable reliability (Cronbach's $\alpha=0.67$; Guttman $=0.67)$, and that the six items present adequate discrimination indices, ranging from 0.305 to 0.453 .

Support for Authorities: An ordinal variable, assessed with the version of the scale utilized by Tyler [19], and composed of eight items which evaluate the degree of support and positive feelings toward legal authorities. The response scale for each item ranges from $0=$ "Disagree strongly" to $10=$ "Agree strongly". The total score for the variable for each participant is the sum of the scores for each of the items. High scores reflect strong support for authority. The psychometric analyses performed indicate that the scale has an acceptable reliability (Cronbach's $\alpha=0.82$; Guttman $=0.60$ ), and that the eight items present adequate discrimination indices, ranging from 0.493 to 0.585 .

\subsection{Instrument}

For the evaluation of all of the variables included in the study, an ad hoc survey was developed with the collaboration of experts in criminal law, officers from the local police department in Elche (Alicante), and two psychometricians. The instrument was developed following in the line of other research in the area of behavior and legal compliance such as Tyler [19] in the United States, and Oceja et al. [26], who used samples of Spanish, Chilean, and American participants.

\subsection{Procedure}

The surveys were administered using the CATI (Computer Assisted Telephone Interview) System, and included both land lines and mobile phones. The duration of each survey was approximately $25 \mathrm{~min}$, and the database of 570 valid surveys was collected over a period of two weeks.

Given the exploratory nature of the research objectives, as well as the lack of earlier robust models for joint analysis that prioritize the variables within the model, we chose to carry out a multiple binary logistic regression analysis, using the Wald forward selection method to build the models. 


\section{Results}

Before the construction of the models used in this article, a bivariate analysis of all the variables was completed in order to identify the magnitude of the relationship between each independent variable and the obedience to the norms; it was also used to determine the possible existence of multi-colinearity in the predictor variables. The only significant finding was a high correlation between the variables "Adequacy of the Limits" and "Valuation of the Limits" ( $\mathrm{r}_{\text {Speed }}=0.67$; $\left.\mathrm{r}_{\text {Alcohol }}=0.6\right)$. Based on this finding the decision to use only Valuation was made because it includes the information of what is intended to evaluate with both variables (how adequate are the limits of each nor perceived). Lastly, while the authors are confident that the methods and model for this study are well-established, the reader is urged to use caution because this research does not intend to draw firm policy conclusions or generalizations from a single study. Instead, what is discussed below is a general assessment and description of the criteria used for making decisions about obeying current traffic law by Spanish drivers.

\subsection{Modeling Compliance with Speed Limits}

In order to assess the suitability of the logistic regression model, several tests of goodness of fit were used, with results shown in Table 2. Omnibus tests of the model coefficients allow for rejection of the null hypothesis: that the regression coefficients of all the terms included in the model are zero. The results of the Hosmer-Lemeshow test indicate that the model fits the data well. Finally, Nagelkerke's $\mathrm{R}^{2}$ generalized coefficient of determination has a value of 0.26 after the addition of the final predictive variable selected, which is considered of moderate magnitude.

Table 2. Goodness of fit at each step (model of compliance with the speed limits).

\begin{tabular}{|c|c|c|c|c|c|c|c|c|}
\hline & \multirow{2}{*}{ Variables } & \multicolumn{3}{|c|}{ Omnibus Tests } & \multicolumn{3}{|c|}{ Hosmer-Lemeshow Test } & \multirow{2}{*}{ Nagelkerke $\mathbf{R}^{2}$} \\
\hline & & $X^{2}$ & gl & $p$ & $X^{2}$ & gl & $p$ & \\
\hline \multirow{2}{*}{ Step 1} & Descriptive norm group & 41.33 & 1 & 0.00 & \multirow{2}{*}{6.31} & \multirow{2}{*}{7} & \multirow{2}{*}{0.5} & \multirow{2}{*}{0.01} \\
\hline & Model & 41.33 & 1 & 0.00 & & & & \\
\hline \multirow{2}{*}{ Step 2} & Experience sanctions & 35.17 & 1 & 0.00 & \multirow{2}{*}{5.31} & \multirow{2}{*}{8} & \multirow{2}{*}{0.72} & \multirow{2}{*}{0.17} \\
\hline & Model & 76.5 & 2 & 0.00 & & & & \\
\hline \multirow{2}{*}{ Step 3} & Certainty accidents & 25.23 & 1 & 0.00 & \multirow{2}{*}{5.93} & \multirow{2}{*}{8} & \multirow{2}{*}{0.66} & \multirow{2}{*}{0.23} \\
\hline & Model & 101.72 & 3 & 0.00 & & & & \\
\hline \multirow{2}{*}{ Step 4} & Feeling of obligation & 9.6 & 1 & 0.00 & \multirow{2}{*}{9.79} & \multirow{2}{*}{8} & \multirow{2}{*}{0.28} & \multirow{2}{*}{0.25} \\
\hline & Model & 111.33 & 4 & 0.00 & & & & \\
\hline \multirow{2}{*}{ Step 5} & Certainty sanctions & 5.53 & 1 & 0.02 & \multirow{2}{*}{6.24} & \multirow{2}{*}{8} & \multirow{2}{*}{0.62} & \multirow{2}{*}{0.26} \\
\hline & Model & 116.86 & 5 & 0.00 & & & & \\
\hline
\end{tabular}

Starting from an estimated cut-off probability of $\mathrm{P}(\mathrm{Y}=1)=0.5$, the model allows for a correct estimation in $71.1 \%$ of cases (Table 3 ). 
Table 3. Number and percentage of cases classified correctly in predicting compliance with the speed limits.

\begin{tabular}{ccccc}
\hline \multirow{2}{*}{ Observed } & \multicolumn{3}{c}{ Predicted } \\
\cline { 3 - 3 } & Comply & 90 & Speed Limit Law & \multirow{2}{*}{ Total } \\
\cline { 3 - 3 } Speed Limits & Comply & Not comply & \\
\hline \multirow{3}{*}{ Not Comply } & 61 & 315 & 394 \\
& Total & 151 & 419 & \\
& \multicolumn{2}{c}{ Overall Percentage Correct } & 71.1 \\
\hline
\end{tabular}

Finally, regression coefficients (B) were obtained for each variable added to the model as well as its standard error (SE), the values and probability associated with the Wald statistic, and the odds ratio (OR) with its confidence intervals (Table 4).

Table 4. Logistic regression model for the probability of compliance with the speed limits.

\begin{tabular}{ccccccc}
\hline Model & B & SE & Wald & $\boldsymbol{p}$ & OR & IC 95\% for OR \\
\hline Descriptive norm group & 0.19 & 0.04 & 27.83 & 0.00 & 1.21 & $1.13-1.29$ \\
Experience sanctions & 1.49 & 0.27 & 30.47 & 0.00 & 4.44 & $2.62-7.54$ \\
Certainty accidents & 0.16 & 0.05 & 11.89 & 0.00 & 1.18 & $1.07-1.29$ \\
Feeling of obligation & 0.03 & 0.01 & 9.1 & 0.00 & 1.03 & $1.01-1.05$ \\
Certainty sanctions & 0.14 & 0.06 & 4.92 & 0.03 & 1.15 & $1.02-1.3$ \\
Constant & -7.06 & 0.87 & 66.47 & 0.00 & 0.00 & \\
\hline
\end{tabular}

On the basis of the results of the model obtained in our sample, it may be concluded that the Odds Ratio (OR) of obeying speed limit laws is (a) 1.21 times larger for Spanish drivers who perceive that their reference group obeys the law; (b) 1.18 times greater for those who perceive a high likelihood of having an accident if they drive too fast; (c) 1.03 times higher for those who express a strong feeling of obligation to obey the law; and (d) 1.5 times greater for those who perceive a high likelihood of being punished if they disobey the law. With respect to the variable for experience with sanctions, based on the odds ratio it should be noted that the OR of compliance is 4.44 times greater for those who have never been sanctioned compared with those who have received some sanction for speeding. However, the results do not appear to be reliable due to the large value of the standard error and the width of the OR confidence interval.

\subsection{Modeling Compliance with Alcohol Limits}

Omnibus tests of the model coefficients indicate that all those which correspond to the variables included in the model are significantly different from zero. The results of the Hosmer-Lemeshow test indicate good model fit (Table 5). The definitive model presents a moderate generalized coefficient of determination, as the Nagelkerke $\mathrm{R}^{2}$ value is 0.23 . 
Table 5. Goodness of fit at each step (model of compliance with the alcohol limit).

\begin{tabular}{|c|c|c|c|c|c|c|c|c|}
\hline & \multirow{2}{*}{ Variables } & \multicolumn{3}{|c|}{ Omnibus Tests } & \multicolumn{3}{|c|}{ Hosmer-Lemeshow Test } & \multirow{2}{*}{ Nagelkerke $\mathbf{R}^{2}$} \\
\hline & & $X^{2}$ & gl & $p$ & $X^{2}$ & gl & $p$ & \\
\hline \multirow{2}{*}{ Step 1} & Valuation of alcohol limit & 49.13 & 2 & 0.00 & \multirow{2}{*}{0.00} & \multirow{2}{*}{1} & \multirow{2}{*}{1} & \multirow{2}{*}{0.14} \\
\hline & Model & 49.13 & 2 & 0.00 & & & & \\
\hline \multirow{2}{*}{ Step 2} & Moral judgment law & 15.11 & 1 & 0.00 & \multirow{2}{*}{1.49} & \multirow{2}{*}{4} & \multirow{2}{*}{0.83} & \multirow{2}{*}{0.18} \\
\hline & Model & 64.24 & 3 & 0.00 & & & & \\
\hline \multirow{2}{*}{ Step 3} & Descriptive norm group & 11.71 & 1 & 0.00 & \multirow{2}{*}{3.97} & \multirow{2}{*}{7} & \multirow{2}{*}{0.78} & \multirow{2}{*}{0.21} \\
\hline & Model & 75.95 & 4 & 0.00 & & & & \\
\hline \multirow{2}{*}{ Step 4} & Certainty accidents & 7.59 & 1 & 0.01 & \multirow{2}{*}{6.73} & \multirow{2}{*}{8} & \multirow{2}{*}{0.57} & \multirow{2}{*}{0.23} \\
\hline & Model & 83.55 & 5 & 0.00 & & & & \\
\hline
\end{tabular}

With an estimated cut-off probability of $\mathrm{P}(\mathrm{Y}=1)=0.5$, the model allows for a correct estimate in $83.3 \%$ of cases (Table 6 ).

Table 6. Number and percentage of cases classified correctly in predicting compliance with the alcohol limit.

\begin{tabular}{ccccc}
\hline \multirow{2}{*}{ Observed } & \multicolumn{3}{c}{ Predicted } \\
\cline { 2 - 3 } & & \multicolumn{2}{c}{ Alcohol Limit Law } & \multirow{2}{*}{ Total } \\
\cline { 2 - 3 } & Comply & 460 & Not Comply & \\
\hline \multirow{3}{*}{ Alcohol Limit } & Not Comply & 84 & 11 & 471 \\
& Total & 544 & 15 & 99 \\
& & Overall Percentage Correct & \\
& & & 26 & 83.3 \\
\hline
\end{tabular}

Once the model's fit was confirmed, logistic regression coefficients were obtained along with their significance and their OR (Table 7). Looking at the interpretation of the results, the OR of complying with the alcohol limit law is (a) 1.28 times greater for those who consider that it is bad to drive drunk; (b) 1.2 times greater for those who perceive that their reference group obeys the law; and (c) 1.18 times greater for those who perceive that the likelihood of having an accident if they exceed the alcohol limit is high (Table 7).

Table 7. Logistic regression model for the probability of complying with the alcohol limit.

\begin{tabular}{ccccccc}
\hline Model & B & SE & Wald & $\boldsymbol{p}$ & OR & CI 95\% for OR \\
\hline Limit adequate & 0.34 & 0.31 & 1.22 & 0.27 & 1.4 & $0.77-2.57$ \\
Limit more strict & 2.02 & 0.46 & 19.55 & 0.00 & 7.56 & $3.08-18.54$ \\
Moral judgment & 0.24 & 0.08 & 9.13 & 0.00 & 1.28 & $1.09-1.49$ \\
Descriptive norm group & 0.18 & 0.05 & 11.64 & 0.00 & 1.2 & $1.08-1.34$ \\
Certainty accidents & 0.17 & 0.06 & 7.84 & 0.01 & 1.18 & $1.05-1.33$ \\
Constant & -4.27 & 0.91 & 21.84 & 0.00 & 0.01 & \\
\hline
\end{tabular}


With respect to the variable valuation of alcohol limit, according to the results shown in Table 7, the OR of obeying this law is 1.4 times greater for those who believe the law to be adequate and 7.56 times greater for those who believe that the law should be stricter, but the magnitude of the standard error of these coefficients of regression and the width of the confidence intervals for the OR indicate that these conclusions may not be reliable.

\section{Discussion and Conclusions}

\subsection{Deterrence and Compliance}

With respect to the speed limit law, the capacity of the perception of the risk of being sanctioned to predict compliance appears to be lower in comparison with the results of bivariate relationships reported in earlier studies [27,28], when analyzed in conjunction with other factors. This is in line with the modest influence of perceived certainty of punishment that has been observed in other studies of compliance [19,29]. In addition, some authors conclude that the relationships found between perception of actual risk and past compliance behavior should not be seen as evidence of the preventive effects of certainty. They should be seen as the effect of one's own experience leading to a reduction in the perceived likelihood of being sanctioned because of the lack of adverse consequences of past law violations [30]. Contrary to what the Deterrence Model hypothesizes, with respect to the alcohol limit law, a relationship between compliance and perceived certainty of being caught/sanctioned was not found; this may indicate that the behavior is determined by motivations other than the mere avoidance of formal punishment.

With regard to severity of punishment, this variable was not added to any of the models as a predictor of compliance. These results are consistent with the low level of actual knowledge of the laws and the applicable sanctions for their violation shown in earlier studies [27,28]. It is also important to remember that the participants were asked to assess how severe the applicable sanctions/punishments taken together were for violation of each of the laws at issue. For this reason, the most reasonable interpretation that can be made of these results is that the observed data may be more indicative of a value judgment about how appropriate or just the sanctions seem in each case, even though we attempted to personalize the severity evaluation for each law through perceived knowledge. This is best supported empirically by the deterrence approach.

In relation to experience with sanctions, in spite of the Deterrence Model's assumptions, there is consistency when people who reported a greater level of non-compliance in the last year are the same people who have been sanctioned because they have violated the law more frequently. This may be the reason why the experience of sanctions has not produced conclusive results for predicting compliance with speed limits, and why, specifically, it has not been added to the model for predicting compliance with drunk-driving laws.

Finally, the perception of risk of traffic accidents from violating legal limits does appear to be related, inversely and significantly, to non-compliance, as the starting hypothesis asserted. It has been added, in addition, to each of the models built for predicting compliance with each law. These results suggest that the importance attributed to these types of costs is greater than that given to perceived characteristics of formal punishment. 


\subsection{Social Influence and Compliance}

The influence of the prescriptive norm was not significant enough to predict compliance with either of the traffic laws considered. When its influence is analyzed in conjunction with other variables, the results of the models demonstrate that perception of the reference group's behavior is the most important predictor of compliance with speed limits, and the second most important predictor of compliance with alcohol limits. The low influence of perceived social disapproval on motivating respect for alcohol limits, compared with the weight exercised by the group's behavior in the same regard, is consistent with what has been observed in other studies, where the descriptive norm seems to predict behavior better than the prescriptive norm when both are present and are equally accessible $[31,32]$.

\subsection{Legitimacy and Compliance}

The results suggest that drivers make moral judgments about each law based on different factors. The majority considers drunk driving to be unacceptable, independently of the established legal limit by means of which the behavior is formally sanctioned [28]. It is consistent, therefore, that compliance is not determined by the perceived adequacy of the alcohol limit but rather by moral judgment of the law, which is also the predictive variable with the greatest weight in the regression model and offers evidence to support the Self-Regulation Model [20].

With regard to speed limits, when the joint influence of moral judgment of the law and adequacy of the limits is analyzed in the presence of other factors, it loses its predictive power and is not included in the model. These results are congruent with the opinion of the majority of drivers, that they should be allowed to drive faster, which seems to indicate that, in reality, the behavior singled out by the law is not considered as morally incorrect as, for example, driving drunk, as discussed above. Similar findings were obtained in an earlier study [28]. If the conflict that drivers believe, in general, it is bad to drive fast and, at the same time, believe that limits should be less strict is to be reconciled, it must be that drivers' behavior is determined by factors other than these unresolved moral assessments, and a model consistent with this argument must be obtained. In addition, these results may support the mediating role attributed to this variable, from which it may be concluded that the predictive capacity of moral judgment of the law may be lessened in the presence of a highly conformist orientation toward the law [26], as occurs with the sample participants, and as will be discussed below.

On the other hand, with respect to compliance with alcohol limits, the results suggest that the predictive weight of the morality attributed to the law is so great that drivers are more motivated by it than by the legitimacy attributed to the legal system and authorities. Of these two variables, only the one related to a feeling of obedience to the law has been added to the model for compliance with speed limits, even though its predictive power is fairly small. These results may signal a conflict between legitimacy and morality that has resolved itself in favor of legitimacy, perhaps because the inconsistency of moral judgment of the law expressed by the drivers in the sample, as discussed above.

In general, the results produced by the different indicators of perceived legitimacy in relation to compliance with each of the laws are consistent with the development of the concept of the perverse norm proposed by Fernández-Dols [33,34]. The majority opinion that drivers should be allowed to go faster, the perception of the injustice of sanctions for speeding, as well as the frequent violation of 
speed limits by Spanish drivers, appear to suggest that these limits could be considered perverse. It is, therefore, reasonable to think that compliance with them is more motivated by factors other than the threat of formal punishment when its perceived probability is high, and to a greater extent, by the behavior adopted by the reference group, which constitutes an accepted social norm. This argument is consistent with the model obtained for compliance with speed limits. As Robinson notes, "people who come to believe that the legal codes deviate importantly from their own moral codes feel lessened concerns with abiding with the law" ([35], p. 202).

By way of conclusion, the results demonstrate the need for a revision of the assumptions upon which public policies are currently based with regard to preventing dangerous driving behavior. Drivers' behavior as to each of the traffic laws considered is significantly different and, therefore, applying common strategies of formal social control in order to encourage responsible driving behavior may be ineffective. No evidence has been found that perception of the severity of punishment associated with the violation of laws has a deterrent effect — not even perceived certainty of punishment when it comes to speed limits, as the probability of compliance with laws seems to depend fundamentally on two factors: on the one hand, the behavior adopted by the reference group, and on the other hand, that the formal laws imposed are considered morally acceptable. It would be advisable, therefore, that formal laws and treatment by legal authorities correspond to the value system shared by members of society.

\section{Limitations and Future Research}

Despite the fact that the main interest of the present investigation was to create a model that would provide a possible explanation as to why people obey norms, that is, what variables seem to have more weight at the moment that a decision is made when a driver encounters a situation in which the law could be broken, the truth is that it would have been interesting to create models that explain transgression of the law. This will be considered in future research within this line of inquiry.

On the other hand, it is worth asking if the factors that appear to explain the obedience/transgression of the norms will have a different weight as a function of individual differences such as the morals of each individual and the variability of the judgments that drivers make about each of the norms they encounter. This question opens a new line of research that will allow, in the future, for continued development of scientific understanding in this discipline, by discovering the keys to an improved prevention of dangerous driving.

Lastly, this study needs to be replicated and findings confirmed before any substantive review of relevant laws needs to be undertaken.

\section{Acknowledgements}

This study was supported by Ministry of Science e Innovation of Spain (research project DER2009-09256, subprogram JURI).

\section{Author Contributions}

Rebeca Bautista authored the first draft and then Sitges and Tirado added their comments and inputs which were incorporated into the final version. The article was co-edited by all authors. 


\section{Conflicts of Interest}

The authors declare no conflict of interest.

\section{References}

1. Raymond Paternoster. "How much do really know about criminal deterrence?" The Journal of Criminal Law and Criminology 100 (2010): 765-824.

2. Lance Lochner. "Individual perceptions of the criminal justice system." American Economic Review 97 (2007): 444-60.

3. Thomas A. Loughran, Greg Pogarsky, Alex R. Piquero, and Raymond Paternoster. "Reassessing the certainty effect in deterrence theory using insight from prospect theory." Justice Quarterly 29 (2012): 712-41.

4. Ross L. Matsueda, Derek A. Kreager, and David Huizinga. "Deterring delinquents: A rational choice model of theft and violence." American Sociological Review 71 (2006): 95-122.

5. Ray Paternoster. "The deterrent effect of the perceived certainty and severity of punishment: A review of the evidence and issues." Justice Quarterly 4 (1987): 173-217.

6. Daniel S. Nagin, and Greg Pogarsky. "Integrating celerity, impulsivity, and extralegal sanction threats into a model of general deterrence: Theory and evidence." Criminology 39 (2001): 865-92.

7. Cesare Beccaria. De los Delitos y las Penas. Madrid: Aguilar, 1969.

8. George Loewenstein. "Anticipation and the valuation of delayed consumption." The Economic Journal 97 (1987): 666-84.

9. Travis C. Pratt, Francis T. Cullen, Kristie R. Blevins, Leah E. Daigle, and Tamara D. Madensen. "The empirical status of deterrence theory: A meta-analysis." In Taking Stock. The Status of Criminological Theory. Edited by Francis T. Cullen, John Wright and Kristie Blevins. New Brunswick: Transaction Publishers, 2006, pp. 367-95.

10. Robert F. Meier, Steven R. Burkett, and Carol A. Hickman. "Sanctions peers, and deviance: Preliminary models of a social control process." The Sociological Quarterly 25 (1984): 67-82.

11. Steven R. Burkett, and David A. Ward. "A note of perceptual deterrence, religiously based moral condemnation, and social control." Criminology 31 (1993): 119-34.

12. Raymond Paternoster, and Sally Simpson. "Sanction threats and appeals to morality: Testing a rational choice model of corporate crime." Law and Society Review 30 (1996): 549-84.

13. Robert B. Cialdini, Raymond R. Reno, and Carl A. Kallgren. "A focus theory of normative conduct: Recycling the concept of norms to reduce littering in public places." Journal of Personality and Social Psychology 58 (1990): 1015-26.

14. Robert B. Cialdini, Carl A. Kallgren, and Raymond R. Reno. "A focus theory of normative conduct: A theoretical refinement and reevaluation of the role of norms in human behavior." In Advances in Experimental Social Psychology. Edited by Leonard Berkowitz. San Diego: Academic Press, 1991, pp. 201-34.

15. Muzafer Sherif. The Psychology of Social Norms. New York: Harper, 1936.

16. Leon Festinger. "A theory of social comparison processes." Human Relations 7 (1954): 117-40.

17. Robert B. Cialdini, and Melanie R. Trost. "Social influence: Social norms, conformity, and 
compliance." In The Handbook of Social Psychology. Edited by Daniel T. Gilbert, Susan T. Fiskey and Gardner Lindzey. New York: McGraw-Hill, 1998, pp. 151-92.

18. Doris Layton MacKenzie. "Reducing the criminal activities of known offenders and delinquents: Crime prevention in the courts and corrections." In Evidence-Based Crime Prevention. Edited by Lawrence W. Sherman, David P. Farrington, Brnadon C. Welsh and Doris Layton MacKenzie. London: Routledge, 2002, pp. 303-404.

19. Tom R. Tyler. Why People Obey the Law. Princeton: Princeton University, 2006.

20. Tom R. Tyler. "Legitimacy and criminal justice: The benefits of self-regulation." Ohio State Journal of Criminal Law 7 (2009): 307-59.

21. Jason Sunshine, and Tom R. Tyler. "The role of procedural justice and legitimacy in shaping public support for policing." Law and Society Review 37 (2003): 513-48.

22. Kevin M. Carlsmith, John M. Darley, and Paul H. Robinson. "Why do we punish? Deterrence and just deserts as motives for punishment." Journal of Personality and Social Psychology 83 (2002): 284-99.

23. Tom R. Tyler. "Psychological perspectives on legitimacy and legitimation." Annual Review of Psychology 57 (2006): 375-400.

24. Tom R. Tyler, Lawrence Sherman, Heather Strang, Geoffrey C. Barnes, and Daniel Woods. "Reintegrative shaming, procedural justice, and recidivism: The engagement of offenders' psychological mechanisms in the Canberra RISE drinking-and-driving experiment." Law and Society Review 41 (2007): 553-86.

25. Francisco Tortosa Gil, and Cristina Civera Mollá. "Es necesario controlar las conductas de consumo." Revista Española de Drogodependencias 36 (2011): 245-48.

26. Luis V. Oceja, José Miguel Fernández-Dols, Angélica González, Isabel Jiménez, and Jaime Berenguer. "¿Por qué cumplimos las normas? Un análisis psicosocial del concepto de legitimidad." Revista de Psicología Social 16 (2001): 21-41.

27. Rebeca Bautista. "La Obediencia a las Normas de Tráfico: Predictores Psicosociales del Cumplimiento Normativo tras la Reforma del Código Penal de 2007 en Materia de Seguridad Vial.” Ph.D. Thesis, Miguel Hernández University, Elche, Spain, July 2012.

28. Fernando Miró Llinares, and Rebeca Bautista Ortuño. “¿Por qué cumplimos las normas penales? Sobre la disuasión en materia de seguridad vial." InDret: Revista para el Análisis del Derecho 4 (2013): 1-53.

29. Ray Paternoster, Linda E. Saltzman, Gordon P. Waldo, and Ted G. Chiricos. "Estimating perceptual stability and deterrent effects: The role of perceived legal punishment in the inhibition of criminal involvement." The Journal of Criminal Law and Criminology 74 (1983): 270-97.

30. Linda Saltzman, Raymond Paternoster, Gordon P. Waldo, and Theodore G. Chiricos. "Deterrent and experiential effects: The problem of causal order in perceptual deterrence research." Journal of Research in Crime and Delinquency 19 (1982): 172-89.

31. Bram P. Buunk, and Arnold B. Bakker. "Extradyadic sex: The role of descriptive and injunctive norms." Journal of Sex Research 32 (1995): 313-18.

32. Melissa A. Lewis, and Clayton Neighbors. "Social norms approaches using descriptive drinking norms education: A review of the research on personalized normative feedback." Journal of American College Health 54 (2006): 213-18. 
33. José Miguel Fernández Dols. "Procesos escabrosos en psicología social: El concepto de norma perversa." Revista de Psicología Social 7 (1992): 243-55.

34. José Miguel Fernández Dols. "Efectos cotidianos de las normas perversas en la tolerancia a la corrupción." Revista de Psicología Social 9 (1994): 3-12.

35. Paul H. Robinson. Principios Distributivos del Derecho Penal: A Quién Debe Sancionarse y en qué Medida. Madrid: Marcial Pons, 2012.

(C) 2015 by the authors; licensee MDPI, Basel, Switzerland. This article is an open access article distributed under the terms and conditions of the Creative Commons Attribution license (http://creativecommons.org/licenses/by/4.0/). 